\title{
Research on Shandong Provincial New-type Urbanization Driving-force Mechanism
}

\author{
Yanan Wang \\ Shandong Yingcai University, Ji'nan, 250000, China
}

Keywords: Shandong province; New-type urbanization; Driving-force mechanism

\begin{abstract}
On the basis of exploration on new-type urbanization theory, this paper specifies the connotation of urbanization and new-type urbanization, analyzes major significance of Shandong provincial new-type urbanization, and then analyzes the driving-force mechanism of Shandong provincial new-type urbanization from aspect of government guidance, market leading, and farmers driving, and finally discusses the strategies of promoting Shandong provincial new-type urbanization process from aspect of insisting on combination of government guidance and market orientation, scientific deployment and planning, promoting industrial transformation and upgrading, and changing the urbanized development mode.
\end{abstract}

\section{Introduction}

Since the $21^{\text {st }}$ century, to promote the urbanization has become the inevitable development trend under the background of rapid economic development. As one of big economic provinces in China, Shandong province also conducts new-type urbanization. Meanwhile, in the list of new-type urbanization pilots officially released by the state on December 29, 2014, there are two pilots in Shandong province, that is, Dezhou City and Weihai City. Through analysis on driving-force mechanism of new-type urbanization, it is able to help to promote healthy development of new-type urbanization, and find out the source power which promotes urbanization. Therefore, the exploration on relevant problems of driving-force mechanism of new-type urbanization is of important realistic significance.

\section{Theoretical exploration on new-type urbanization}

\section{Theoretical overview}

The urbanization is a critical index used to measure level of modernization. Generally speaking, the urbanization refers to the situation that the non-agricultural industries enter into cities, the rural population moves into cities, and the range of cities is gradually expanded to rural area in the process of industrialized development. If the things go on like this, the quantity and scale of cities will increase, the urban culture and lifestyle will gradually penetrate into rural area, and this development process is called urbanization.

The new-type urbanization mode is to formulate the scheme of coordinating the development of urban and rural area, carrying out reasonable construction, saving land resource, and complete functions, establishing urbanization mechanism under the help of market and government, and promote the virtuous circle of urbanization and industrialization, informatization, and agricultural modernization. Through reasonable urban and rural planning, it is able to promote the coordinated development, and form a low-carbon, green, and harmonious sustainable urbanization development road with little waste of resources, little environmental pollution, high economic benefits, and urban-rural integration.

\section{Significance of promoting new-type urbanization in Shandong province}

The significance of new-type urbanization in Shandong province is reflected at following aspects.

Firstly, the urbanization is the only way for modernization.

To keep mutual coordination and synchronous development of urbanization, industrialization, informatization, and agricultural modernization is also the key point of modernized construction. The 
industrialized development is the source of power; the agricultural modernization is the basic guarantee; the informatization has potential power and provides vitality for development; the urbanization provides development carrier and platform and promotes progress in industrialization and informatization, and it is a powerful backup force which helps the agriculture to realize modernized development and promotes the modernization steps of Shandong province.

Secondly, the new-type urbanization is the inevitable requirement for quickening to construct a strong economic and cultural province.

The urbanization is closely related to social development and economic growth; the implementation of new-type urbanization is the precondition for modernized development of Shandong province, and also the core content of constructing a strong economic and cultural province. In order to promote the construction of well-off society, Shandong province must improve the strategic position of new urbanization, and provide strong power support for continuous social development and stable economic growth so as to lay a firm foundation for Shandong people to realize the goal of economic development.

Thirdly, the new-type urbanization is an important support for changing the way of economic development.

The urbanization of current resident population in Shandong province accounts for about 53.75\%, which is much lagging compared to that in developed areas. The improvement of urbanization level promotes continuous expansion and upgrading of consumer group, consumption structure, and consumption potential; however, as for urban public infrastructure and necessary facilities for residences, the construction and investment shall be expanded. It is required to optimize and reasonably allocate the urban and rural production factors, improve labor productivity and resource utilization efficiency, and promote the improvement of industrial innovation ability and their own optimization and upgrading.

\section{Driving-force mechanism for Shandong provincial new-type urbanization}

The driving-force mechanism of urbanization is mainly reflected at ensuring stable development of urbanization to provide power support, and maintaining and improving the system which consists of economic relation and organizational system. The power source for urbanization in Shandong province is shown as below.

\section{Government guidance}

The government plays a dominant role in Chinese urbanization, and the urbanization is a kind of urbanization for which the government provides guidance power. In both developed countries and developing countries, they realize the urbanization through market leading, and industrialized and urbanized expansion; as a developing country, the agricultural economy in China accounts for a large proportion. The main body of industrialization and urbanization is the government and state, and this is also the feature of systematic construction. The government plays three aspects of functions in urbanization. Firstly, it is formulating urbanization strategy, giving priority to building small cities, and then promoting urbanization development; secondly, the government carries out reasonable arrangement, determines plan, and establish the system for the urbanization; thirdly, the governments at different levels play a dominant role in the urbanization process.

Shandong province has proposed new-type urbanization planning of 2014-2020; according to the important instructions given in the documents such as Opinions of CPC Shandong Provincial People's Government on Promoting New-type Urbanization Development and Shandong Provincial Main Functional Area Planning, it is able to drive Shandong province to move toward the goal of macro, strategic, and fundamental new-type urbanization only through specifying strategic goal, planned task and implementation means of urbanization, and providing innovation thinking for systems and policies. Meanwhile, in recent years, CPC and government have paid more and more attention to the development of infrastructure in Shandong region and have obtained certain result, which provides main power in urbanization process. 


\section{Market leading}

The market is an effective way to realize optimal resource allocation. Through market competition, it is able to improve market vitality. Through market leading, it is able to realize free circulation of various kinds of production elements, quicken urbanization process, and promote new-type urbanization development. The current reform and development of market economy is to change the mode of uniform management by government, and establish the from-bottom-to-top development mode. And this kind of development mode is gradually developed into the key and power which promotes the new-type urbanization development. In the process of promoting new-type urbanization, a fundamental task is to effectively solve the configuration of production elements in urban and rural areas. Through reasonable configuration and optimization of various kinds of production elements, it is able to exert the important function of market in promoting new-type urbanization and promote an orderly development of urbanization.

\section{Farmers driving}

In the process of promoting urbanization, the farmers driving plays an important role. Therefore, whether it is able to organize and motivate wide farmers is the key which determines whether the new-type urbanization succeeds or fails. As the most direct participants in urbanization process, the farmers hope that the new-type urbanization can be successful, but they also have a psychology of entanglement. On one hand, farmers hope that they can live a more decent life and enjoy the treatment same with citizens; on the other hand, they feel worried in consideration of unknown risk and changes. Meanwhile, farmers' survival rationality and calculation rationality provide strong pushing force for new-type urbanization.

Meanwhile, the continuous development of market economy provides more selection chances for farmers' employment, which causes fundamental changes in agricultural structure. Under the pushing of policies which promote new-type urbanization, the great consumption demand and investment demand, as well as large quantity of employment chances, are brought. Since the implementation of reform and opening up policy in 1978, Chinese farmers have gradually released from land and devote themselves into tertiary industry, which creates a condition for scale-based operation of Chinese rural areas. Furthermore, large quantity of farmers flow into cities and obtain more income through engaging in business and other ways, which quickens the urbanization process.

Shandong province is a large province of traditional agricultural production; however, the agricultural land and water resource is scarce, with large rural population and few per capita cultivated land area, thus it is hard for peasant household to realize scale operation, which causes the situation that it is hard to effectively change traditional way of production and the barrier is formed for construction of well-off society. Through promoting urbanization process, it is able to output rural surplus labor to cities and further improve rural living standard, as well as effectively improve land utilization efficiency and create more powerful condition for agricultural scale operation.

\section{Research on strategies of promoting Shandong new-type urbanization process}

\section{Combination of government guidance and market leading}

From perspective of driving-force mechanism, we can regard urbanization process as an organic combination of government behavior and market mechanism to provide chances for concentrated flow of rural population toward cities, thus causing cluster of industrial space and gradual change of people's lifestyle and concepts. Therefore, in the urbanization process, it is inevitable that the gathering of production elements and higher-efficiency configuration will happen; in this process, we shall fully exert the resource configuration function of market, follow the operation rule of market economy, and avoid the appearance of man-made market marking.

In the process of urbanization development, we shall fully exert resource allocation and regulation function of market, and also exert regulation function of government. Only after organic combination of fundamental function of market on resource allocation and overall function of government, we can reasonably guide development speed and scale of urbanization, and optimize the structure and layout of urban development. 


\section{Scientific deployment and planning, quickening the adjustment of industrial development and industrial structural layout}

As a large agricultural province, Shandong shall pay more attention to promoting the industrial development and the transformation and upgrading of industrial structure so as to drive the development of urbanization in the process of promoting new-type urbanization. Firstly, we shall greatly promote the development of industries in middle and west Shandong with lagging economy. In those areas, through industrial rapid development and prosperity, it is able to drive the increase of employment figure and guide rural population to rapidly flow into cities. As for middle and west areas, they shall form strategic leading industries with regional features so as to promote the rapid development of strategic emerging technical industry and modern service industry. Secondly, it is required to greatly promote the strategic transformation and upgrading of industrial structure in east Shandong.

The level of Shandong provincial urbanization development is a leading level in China, and its dominant role in Shandong provincial economic development is very obvious; meanwhile, we shall be aware that that the high-tech industrial development level of Shandong province is still low, which causes certain barrier on urbanization development. Therefore, Shandong province shall make use of deep adjustment of industrial structure to promote high-tech industrial development so as to form the modern industry with rapidly developed emerging industry and ocean industry. Thirdly, it is required to transfer partial industries in east Shandong to middle or west Shandong so as to promote the optimization and adjustment of industrial structure in Shandong province. Finally, the production elements shall be inclined to the cities in middle and west cities so as to realize the policy distribution of production elements and production resource in Shandong province and promote great development of urbanization process in middle and west Shandong.

\section{Changing the development mode of urbanization and stepping on a road of new-type urbanization}

In the process of new-type urbanization, we shall change the development mode of urbanization, step on a road of new-type urbanization, and promote a coordinated development of urbanized economic development and ecological environment.

Firstly, we shall formulate innovation-based urban development strategy. In the process of urbanization development, we shall establish innovation awareness, promote the innovation of development mode, realize continuous optimization and improvement of basic environmental condition, and improve the efficiency of input and output, as well as pay attention to the market transformation of innovation result in the process of urbanization.

Secondly, in the urbanization process, we shall advocate resource saving, and step on the road of low-carbon development. In the specific development process, we shall greatly improve land utilization rate, and step on the road of intensive development. As for basic construction or enterprise development in some cities, we shall focus on uncultivated-place planning and development. The counties or villages with condition and foundation can develop toward intensification of village-town combination.

Thirdly, we shall step on the road of urbanization development under the strategy of environmental protection. In the process of following environmental protection and ecological urbanization development, Shandong province has clearly required that all towns shall promote the urbanization according to construction goal of ecological towns. While continuously deepening the degree of new-type urbanization, we shall insist on ecological development concept and insist on the road of environmentally friendly, and low-carbon resource-saving urbanization.

\section{Conclusion}

In conclusion, to promote urbanization, and realize synchronous development and mutual supplement between urbanization and industrialization, between agricultural modernization and informatization has become the core content of promoting socialist modernization. Meanwhile, to promote new-type urbanization is also a necessary requirement to develop Shandong province as a 
strong economic and cultural province. As a powerful economic province in China, Shandong province shall actively master the chance of China's carrying out new-type urbanization pilots, quicken the adjustment of industrial development and industrial structural layout from perspective of government guidance, market leading, scientific deployment and planning, and change the development mode of urbanization so as to provide power for promoting Shandong provincial new-type urbanization.

\section{Acknowledgments}

This paper is a fund project: Research on Shandong Provincial New-type Urbanization Driving-force Mechanism, with a serial number of 14CGLJ44.

\section{References}

[1] Li Meng: Research on Cultural Driving-force Mechanism of China's New-type Urbanization, Reformation \& Strategy, 2014, 11: 104-107+115.

[2] People’s Bank of China Nanchang Central Sub-branch Office Research Group, Guo Yunxi: Research on Financial Driving-force Mechanism of Urbanization - Empirical Analysis Based on Jiangxi, Finance and Economy, 2014, 02: 85-88.

[3] Xu Jun: Perfect Financial Driving-force Mechanism of New-type Urbanization in Jiangxi, China National Conditions and Strength, 2014, 07: 45-47.

[4] Zhang Jie: Research on Driving-force Mechanism of Featured Urbanization in Xinjiang, Shihezi University, 2011.

[5] Wang Yiqi: Research on Urbanization Development Mechanism in Coastal Region of Shandong, Chongqing University, 2011. 